\title{
Overview of the Pathogenesis of ANCA-Associated Vasculitis
}

\author{
Hong Xiao Peiqi Hu Ronald J. Falk J. Charles Jennette \\ Department of Pathology and Laboratory Medicine, School of Medicine, University of North Carolina at Chapel Hill, \\ Chapel Hill, N.C., USA
}

\section{Key Words}

ANCA - Antineutrophil cytoplasmic autoantibodies .

Autoantibodies · Polyangiitis · Vasculitis

\begin{abstract}
Background: Antineutrophil cytoplasmic autoantibodies (ANCA) are associated with a spectrum of necrotizing vasculitis including granulomatosis with polyangiitis, microscopic polyangiitis, eosinophilic granulomatosis with polyangiitis, and renal-limited necrotizing and crescentic glomerulonephritis. Clinical observations and in vitro and in vivo experimental evidence strongly indicate that ANCA are pathogenic. Summary: The etiology and pathogenesis of ANCA-associated vasculitis (AAV) are multifactorial, with contributions from genetic factors, environmental exposures, infections, characteristics of the innate and adaptive immune system, and the intensity and duration of the injury. Acute vascular inflammation is induced when resting neutrophils that have ANCA autoantigens sequestered in cytoplasmic granules are exposed to priming factors - for example, cytokines induced by infection or phlogogenic factors released by complement activation - that cause the release of ANCA antigens on the surface of neutrophils and in the microenvironment around the neutrophils. ANCA bind to these ANCA antigens, which
\end{abstract}

activates neutrophils by $\mathrm{Fcy}$ receptor engagement and $\mathrm{F}\left(\mathrm{ab} \mathrm{b}_{2}\right)_{2}$ binding at the neutrophil cell surface. ANCA-activated neutrophils release factors that activate the alternative complement pathway, which generates $\mathrm{C} 5 \mathrm{a}$, a chemoattractant for neutrophils; $\mathrm{C} 5 \mathrm{a}$ also primes the arriving neutrophils for activation by ANCA. Activated neutrophils adhere to and penetrate vessel walls, and they release toxic oxygen radicals and destructive enzymes that cause apoptosis and necrosis of the neutrophils as well as of the adjacent vessel wall cells and matrix. Key Messages: Patients with active AAV have ongoing asynchronous onsets of countless acute lesions, with each lesion evolving through stereotypical phases within 1 or 2 weeks. Induction of remission results in termination of new waves of acute lesions and allows all lesions to progress to scarring or resolution. $\quad 2015 \mathrm{~S}$. Karger AG, Basel

\section{Introduction}

Antineutrophil cytoplasmic autoantibody (ANCA)associated vasculitis (AAV) is a category of vasculitis and predominantly involves small vessels (arteries, arterioles, venules, and veins) in any organ of the body $[1,2]$. AAV pathogenic mechanisms should explain the pathologic

\section{KARGER 125}

(c) 2015 S. Karger AG, Base

2296-9381/15/0014-0205\$39.50/0

E-Mail karger@karger.com

www.karger.com/kdd
J. Charles Jennette, MD, Kenneth M. Brinkhous Distinguished Professor and Chair

Department of Pathology and Laboratory Medicine, School of Medicine University of North Carolina at Chapel Hill

308 Brinkhous-Bullitt Building, CB\#7525, Chapel Hill, NC 27599-7525 (USA)

E-Mail jcj@med.unc.edu 
Fig. 1. Pathology of AAV. a, c Acute leukocytoclastic angiitis in a patient with AAV (a) and a mouse with a model of AAV induced by the injection of anti-MPO IgG (c). In both a and c, a small vessel has mural and perivascular influx of leukocytes, including numerous neutrophils, some of which are undergoing leukocytoclasis. b, d NCGN in a patient with AAV (b) and in a mouse with a model of AAV induced by the injection of anti-MPO IgG (d). Note the fibrin in Bowman's space (long arrows) and the cellular crescent (short arrows).

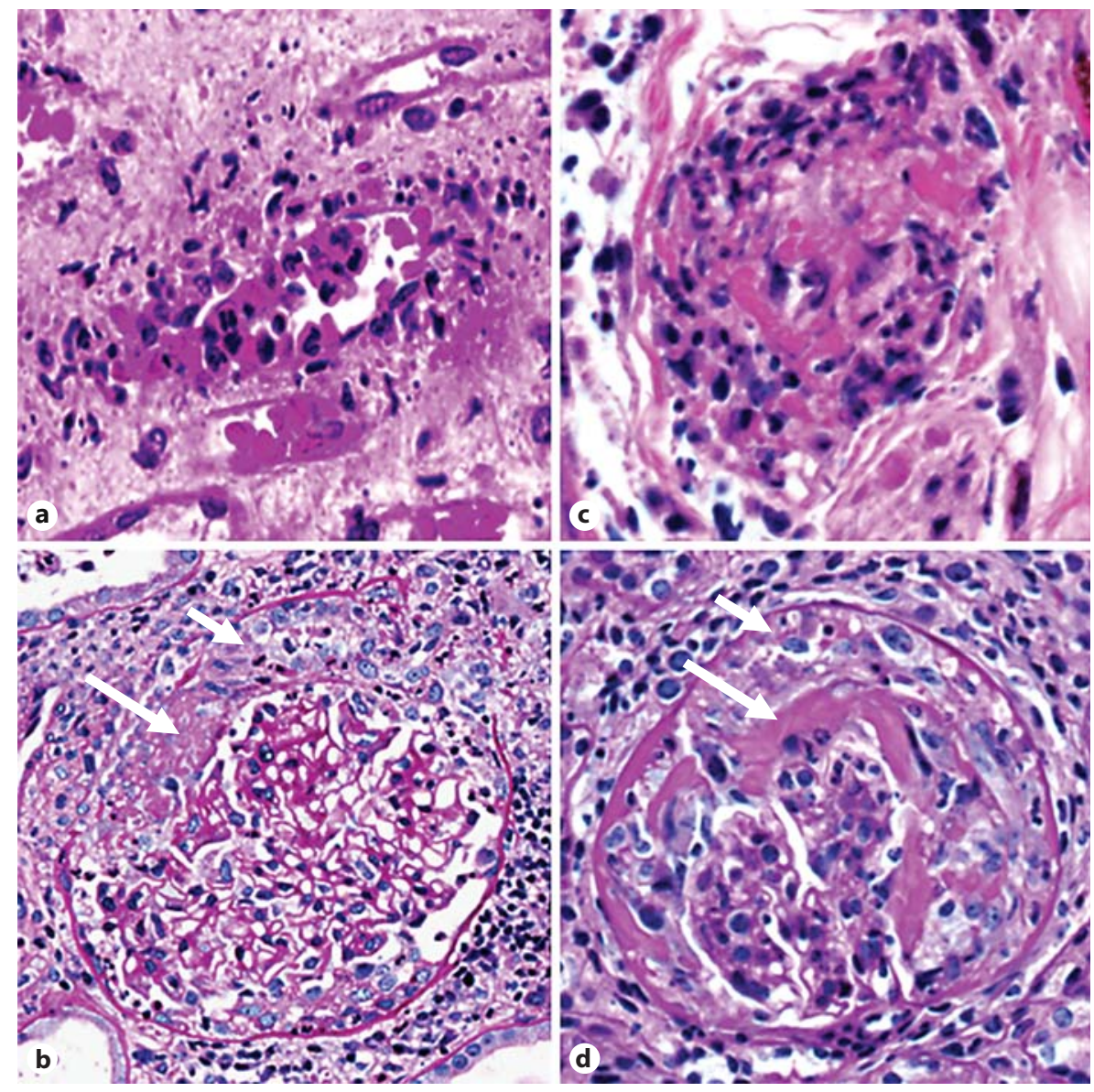

and clinical manifestations of AAV. Pathologically, in the acute phase AAV is characterized by necrotizing vasculitis with infiltrating neutrophils and monocytes (fig. 1) [3]. Within days, the neutrophils undergo leukocytoclasis and disappear, to be replaced by mononuclear leukocytes including macrophages, monocytes, and T lymphocytes. Immunopathologically, AAV is characterized by the absence or a paucity of immunoglobulin deposition in vessel walls, which indicates that the pathogenesis of AAV is different from the pathogenesis of vasculitis, which has extensive vessel wall deposition of immunoglobulin, indicative of immune complex vasculitis or antiglomerular basement membrane disease [1]. AAV has different clinicopathologic phenotypes, including granulomatosis with polyangiitis (GPA; formerly known as Wegener's granulomatosis), microscopic polyangiitis (MPA), eosinophilic GPA (EGPA; formerly known as Churg-Strauss syndrome), and renal-limited necrotizing and crescentic glomerulonephritis (NCGN) [1]. The approximately $10 \%$ of AAV patients who are ANCA negative have clinical and pathologic manifestations similar to those of ANCApositive patients [4], and thus are likely to have a similar if not identical final pathogenic pathway leading to vasculitis.

The two major target antigens for ANCA in patients with vasculitis are myeloperoxidase (MPO) [5] and proteinase 3 (PR3) [6] in the granules of neutrophils and lysosomes of monocytes. Another autoantigen target that has been reported is lysosomal-associated membrane protein 2 (LAMP2) [7], but the frequency of this autoantibody in AAV is not fully understood [8]. The specificity of ANCA for MPO versus PR3 correlates with the spectrum of pathologic and clinical features that is most likely to be found in a given patient [9], with MPO-ANCA patients having more MPA features and PR3-ANCA patients having more GPA features. A genome-wide association study (GWAS) showed that genetic characteristics, including major histocompatibility complex traits, correlated better with ANCA autoantigen specificity than with different kinds of clinicopathologic expression of 
Fig. 2. Diagram depicting the multifactorial influences on the pathogenesis of AAV. Reproduced with slight changes from Jennette and Falk [11] with permission. $\mathrm{MCH}=$ Major histocompatibility complex; $\mathrm{ABS}=$ antigen-binding site.

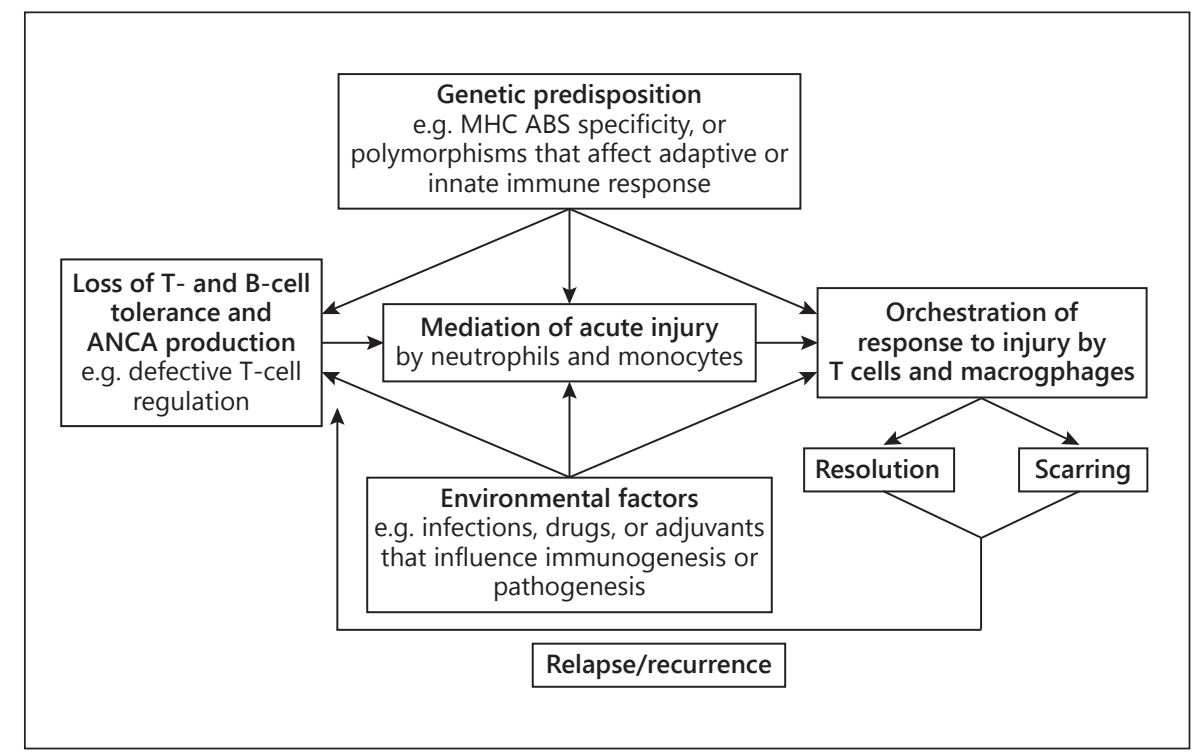

AAV (such as MPA vs. GPA) [10], which is not surprising given the link between the peptide specificity of human leukocyte antigen (HLA) molecules that present antigens and the resulting antigen specificity of T-cell receptors and immunoglobulin antigen-binding domains.

As with most autoimmune diseases, the etiology and pathogenesis of AAV are undoubtedly multifactorial, with contributions from genetic factors, environmental exposures, infections, characteristics of the innate and adaptive immune system, and the intensity and duration of the injury [11]. Among different patients, differing etiologic and synergistic factors may lead to AAV, which may influence the differences in clinicopathologic phenotypes among patients. The pathogenesis of AAV follows the general pattern of other autoimmune inflammatory diseases in that there is a beginning, in which the aberrant pathogenic autoimmune response is generated; an active injury phase, mediated by effector leukocytes that, in the case of AAV, are predominantly neutrophils, and a response-to-injury phase, which, in AAV, predominantly involves monocytes, macrophages, and $\mathrm{T}$ lymphocytes (fig. 2). If the acute injury is mild enough, it will resolve completely (e.g. complete disappearance of a purpuric rash); however, if full resolution is not possible, the outcome is often scarring, which may result in residual dysfunction (e.g. necrotizing glomerular injury leading to glomerular scarring with residual renal insufficiency and proteinuria). It is important to recognize that, based on observations in patients and animal models, patients with active AAV have ongoing asynchronous onsets of count- less acute lesions occurring in multiple organs, with each lesion evolving through the stereotypical phases from acute to chronic, probably over a span of only 1 or 2 weeks. Therapeutic induction of remission results in termination of new waves of acute lesions and allows all lesions to progress to scarring or resolution. Relapse entails the initiation of new waves of acute lesions.

The pathogenic mechanism that will be reviewed in this article describes a sequence of events that does not simply happen once during the course of AAV, but rather continues to occur at multiple sites as long as there is active AAV. Thus, if a patient continues to have active disease, new lesions will appear in the initial acute phase at all times until remission is induced.

\section{Clinical Evidence Supporting the Pathogenicity of ANCA}

A number of clinical observations support the pathogenicity of ANCA. Bansal and Tobin [12] reported a case of transplacental passage of MPO-ANCA from a mother with MPA to a neonate that resulted in neonatal pulmonary hemorrhage and renal disease within days after birth. This report provides direct clinical evidence for the pathogenic role of MPO-ANCA in humans; however, no additional examples of this phenomenon have been reported, and the delivery of a healthy newborn despite transplacental transfer of MPO-ANCA from a mother with MPA was described [13]. 
ANCA small vessel vasculitis is characterized by vascular inflammation that is highly correlated with the presence of ANCA in the circulation of patients. Either MPOANCA or PR3-ANCA are present in $90 \%$ of patients with GPA, MPA, EGPA, and renal-limited NCGN [4]. In general, high levels of ANCA are present in patients with active disease, and the titers fall during therapy; however, this is not an absolute correlation using current clinical assays for ANCA. Epitope-specific assays for ANCA that can identify autoantibodies which are particularly pathogenic may show a better correlation between ANCA titers and disease activity [14].

Another observation in humans that supports a pathogenic role of ANCA is the close association of development of ANCA disease with specific drug treatment, including propylthiouracil, minocycline, pimagedine, hydralazine, and levamisole-adulterated cocaine $[15,16]$. Renal remission typically occurs in these patients after drug withdrawal, immunosuppressive treatment, and decline in ANCA [15-17].

Targeted therapies that reduce autoantibodies and deplete $B$ cells are effective treatments in AAV, supporting a pathogenic role for ANCA. For example, patients who had undergone removal of circulating ANCA by plasma exchange had a lower risk for progression to end-stage renal disease at 1 year than patients who had not received a plasma exchange [18]. Further, depleting B cells - for example, with anti-CD20 antibodies - is effective in the induction of remission and maintenance of remission [19]. This beneficial effect of targeted antibody and B-cell treatments in AAV patients supports a pathogenic role for circulating ANCA.

\section{In vitro Evidence Supporting and Elucidating the Pathogenicity of ANCA}

Numerous in vitro studies have demonstrated that ANCA activate both neutrophils and monocytes. Incubation of MPO-ANCA or PR3-ANCA with normal human neutrophils that have been primed by proinflammatory stimuli such as tumor necrosis factor (TNF)- $\alpha$, bacterial lipopolysaccharide (LPS), or the complement anaphylatoxin $\mathrm{C} 5 \mathrm{a}$ induces a respiratory burst that generates toxic oxygen free radicals and degranulation, which in turn release numerous destructive enzymes to cause injury to and death of cultured endothelial cells [20-30].

ANCA are predominantly IgG class autoantibodies that can engage $\mathrm{F} c \gamma$ receptors $(\mathrm{Fc} \gamma \mathrm{R})$ [23] and can bind to ANCA antigens (such as MPO and PR3) at the surface of primed neutrophils [26], resulting in neutrophil activation [20]. Engagement of $F c \gamma R$ appears to be the major driver of activation. The priming of neutrophils causes autoantigen translocation to the surface of cells, so that $\mathrm{F}\left(\mathrm{ab}^{\prime}\right)_{2}$ of ANCA can interact with the autoantigens [26, 28]. Phosphorylation of p38 mitogen-activated protein kinase and the extracellular signal-regulated kinase are involved in neutrophil priming and activation, and blockade of mitogen-activated protein kinase prevents this priming and activation [27, 31, 32]. Simvastatin, a 3-hydroxy-3-methylglutaryl-coenzyme A inhibitor, is capable of inhibiting the ANCA-induced degranulation of neutrophils [33]. These in vitro finding support a pathogenic role for ANCA and also suggest potential novel therapeutic options for ANCA disease.

In addition to neutrophils, monocytes contain the ANCA antigens MPO and PR3, and can be activated in vitro by ANCA similarly to neutrophils, with a resultant production of proinflammatory cytokines including monocyte chemoattractant protein 1 (MCP-1, also known as CCL2) and IL-8 [34-36]. IL-8 can attract and activate neutrophils and thus could amplify neutrophil-mediated injury. MCP-1 attracts monocytes and macrophages and could participate in the transition of ANCA-induced vascular injury from predominantly neutrophil-rich inflammation to predominantly monocyte- and/or macrophage-rich inflammation, including granulomatous inflammation [36]. Monocytes are conspicuous at sites of ANCA vascular inflammation as early as the first 1 or 2 days, and there is evidence for systemic activation of monocytes in patients with active ANCA-associated disease [37-39].

\section{Animal Model Evidence Supporting and Elucidating the Pathogenicity of ANCA}

The most convincing evidence that autoantibodies with specificity for recognized ANCA autoantigens are pathogenic comes from animal models of AAV. Several animal models of disease caused by ANCA have been described [40]. The first described, and most extensively studied, is a mouse model developed by Xiao et al. [41]. MPO knockout mice were immunized with murine MPO to produce high titers of anti-murine MPO antibodies. Intravenous injection of the purified anti-MPO IgG into wild-type or immunodeficient Rag2-/- mice (lacking immune-competent $\mathrm{B}$ and $\mathrm{T}$ cells) induced pauci-immune NCGN and systemic small vessel vasculitis which closely mimic human ANCA disease (fig. 1) [41]. Depending on 
modulating factors such as infection or modification of innate immune capabilities, mice can be induced to have more or less pulmonary alveolar hemorrhagic capillaritis or necrotizing granulomatosis [unpubl. observations]. Thus, anti-MPO antibodies alone, in the absence of functional $\mathrm{T}$ cells, are sufficient to cause acute lesions virtually identical to human AAV. As will be discussed later, T cells are important in the initial induction and maturation of the autoimmune ANCA response, in the amplification of acute injury, and in the chronic response to acute injury.

Another mouse model was created by transplanting wild-type bone marrow cells with MPO into irradiated MPO knockout mice that had been immunized with murine MPO and had high titers of anti-MPO antibodies. Once the transplanted MPO-positive neutrophils appeared in the circulation, the mice developed glomerulonephritis, whereas control mice that received bone marrow cells from MPO knockout mice did not, demonstrating that induction of glomerulonephritis required both anti-MPO antibodies and MPO-positive neutrophils in the circulation [42].

A rat model has also been reported that supports a pathogenic role for ANCA [43, 44]. Rats immunized with human MPO develop anti-MPO antibodies that crossreact with rat MPO. These rats developed NCGN and pulmonary vasculitis.

No convincing models of PR3-AAV have been widely accepted, although several models have been proposed [45-48]. Because these models use mice, one possible explanation for the failure to produce a model of PR3ANCA disease is that the low level of PR3 in circulating mouse neutrophils is not sufficient to mediate activation by anti-PR3 antibodies.

\section{Neutrophils as Effector Cells in AAV Pathogenesis}

Clinical evidence and in vitro studies suggest that neutrophils are important effector cells in the pathogenesis of human AAV. In renal biopsies from patients, activated neutrophils are present in affected glomeruli, and the number of activated intraglomerular neutrophils correlates with the severity of renal injury as reflected in serum creatinine levels [49]. In vitro, ANCA can activate cytokine-primed neutrophils, causing an oxidative burst, degranulation, release of inflammatory cytokines, and damage to endothelial cells [20-29].

To support the hypothesis that neutrophils are key effector cells in the pathogenesis of MPO-ANCA-mediated NCGN in the experimental model, wild-type mice were

Pathogenesis of ANCA-Associated Vasculitis depleted of circulating neutrophils by injection of antineutrophil monoclonal antibody (NIMP-R14) and then injected with pathogenic anti-MPO IgG. These mice were completely protected from anti-MPO IgG-induced NCGN, while all control mice developed NCGN [50]. These experiments provide direct evidence that neutrophils play a major role in the pathogenesis of anti-MPO-induced NCGN in this animal model and implicate neutrophils in the induction of human ANCA disease. This raises the possibility that therapeutic strategies for reducing circulating neutrophils could be beneficial to patients with ANCAinduced NCGN. This finding does not exclude the possibility that monocytes contribute to lesion induction or progression, but, at least in this model, monocytes are not sufficient to cause the acute necrotizing lesions.

\section{Cytokines and Chemokines in AAV Pathogenesis}

Clinical and experimental evidence indicates that proinflammatory stimuli, for example induced by infections, can be a synergistic factor in the onset, recurrence, and exacerbation of AAV. AAV occurs and relapses more often in winter and spring, when there is a higher incidence of infections [51]. In vitro, anti-MPO IgG induces a respiratory burst of murine neutrophils more effectively after priming with proinflammatory stimuli such as TNF- $\alpha$, LPS, or C5a $[20,30,32,52]$. To test the synergistic effect of proinflammatory factors in the anti-MPO IgG-induced NCGN mouse model, wild-type mice were injected with bacterial LPS as a proinflammatory stimulus along with anti-MPO antibodies [52]. Compared to control mice that received anti-MPO without LPS, mice that receive anti-MPO and LPS developed more severe antiMPO-induced NCGN and had increased levels of circulating TNF. Anti-TNF treatment attenuated the LPS-mediated aggravation of anti-MPO IgG-induced glomerulonephritis.

\section{Complement in ANCA Pathogenesis}

Until animal model experiments demonstrated a major role for complement in the pathogenesis of $\mathrm{AAV}$, complement activation had not been suspected as a major pathogenic factor because of the relative paucity of complement component deposition at sites of vascular inflammation and glomerulonephritis in AAV compared to the more extensive localization of complement at sites of inflammation induced by recognized forms of immune 
complex-mediated inflammation that were known to involve extensive complement activation. The mouse model of anti-MPO IgG-induced NCGN identified an unsuspected role of complement activation [53] that has subsequently been supported by observations in patients [54-59]. The NCGN induced by transfer of anti-MPO IgG into wild-type mice or anti-MPO splenocytes into immunodeficient (Rag2-/-) mice could be completely blocked by complement depletion using cobra venom factor [53]. This finding was confirmed by the failure of C5 knockout mice to develop NCGN after injection of anti-MPO antibodies. The role of specific complement activation pathways was investigated using mice with knockout of classic and lectin-binding pathway component $\mathrm{C} 4$ and alternative pathway component factor B. After injection of anti-MPO IgG, C4 knockout mice developed disease comparable to that in wild-type mice; however, factor B knockout mice developed no disease. These observations demonstrated that the alternative complement activation pathway plays a critical pathogenic role in ANCA-induced NCGN, and that the classic and lectin pathways are not required [53].

A number of subsequent observations in AAV patients support a role for complement activation in pathogenesis, including evidence for complement activation at tissue sites of vascular inflammation and detection of biomarkers for complement activation in plasma and urine [5459]. For example, the complement membrane attack complex C3d and factor B are detected in the lesion sites of patients with AAV [54]. Clinical studies have reported that plasma levels of C3a, C5a, soluble C5b-9, and factor $\mathrm{Bb}$ were higher in active $\mathrm{AAV}$ than in $\mathrm{AAV}$ in remission [56]; that levels of plasma complement factor $\mathrm{H}$, a regulator of the alternative complement activation pathway, were significantly lower in active AAV patients compared with AAV patients in remission and normal controls, and also that plasma factor $\mathrm{H}$ levels were inversely correlated with circulating levels of $\mathrm{C} 3 \mathrm{a}, \mathrm{C} 5 \mathrm{a}$, and Sc5b-9, and positively correlated with circulating levels of C3 [59].

Based on animal model studies $[30,53]$, the activation of $\mathrm{C} 5$ and engagement of $\mathrm{C} 5 \mathrm{a}$ receptor $(\mathrm{C} 5 \mathrm{aR})$ on neutrophils should be critical events in the induction of ANCA disease. To test this hypothesis, mice deficient in $\mathrm{C} 5 \mathrm{aR}$ were injected with anti-MPO IgG. Protection against antiMPO-induced NCGN was observed in these mice [60]. Moreover, transgenic mice with mouse $\mathrm{C} 5 \mathrm{aR}$ replaced by human $\mathrm{C} 5 \mathrm{aR}(\mathrm{C} 5 \mathrm{aR} / \mathrm{CD} 88)$ that were treated with a smallmolecule antagonist of human C5aR/CD88 (CCX168) showed a significant amelioration of anti-MPO-induced NCGN [60]. These observations demonstrate that C5a en- gagement of $\mathrm{C} 5 \mathrm{aR}$ has a critical role in the pathogenesis, and that blockade of C5aR/CD88 might have a therapeutic benefit for patients with AAV and glomerulonephritis [60]. A clinical trial is currently underway to assess the safety and efficacy of CCX168 in patients with AAV.

The in vitro and in vivo studies summarized thus far in this review support the pathogenic sequence for the acute vascular lesion of AAV that is illustrated in figure 2 [61]. Beginning in the upper left of the illustration, resting neutrophils have the target ANCA autoantigen sequestered in cytoplasmic granules. Exposure to priming factors, for example cytokines induced by a synergistic infection or phlogogenic factors released by complement activation, causes priming of neutrophils with release of ANCA antigens (e.g. MPO and PR3) on the surface of the neutrophils and in the microenvironment around the neutrophils [20, 22,52 ]. If ANCA are present in the plasma, they bind to ANCA antigens and activate neutrophils by $\mathrm{Fc} \gamma \mathrm{R}$ engagement and $\mathrm{F}\left(\mathrm{ab}^{\prime}\right)_{2}$ binding at the neutrophil cell surface $[23,25,26]$. ANCA-activated neutrophils release factors that activate the alternative complement pathway $[53,60]$, which generates $\mathrm{C} 5 \mathrm{a}$, a chemoattractant for the accumulation of more neutrophils at the site of activation. C5a also primes the arriving neutrophils for activation by ANCA $[30,60]$. The activated neutrophils adhere to and penetrate vessel walls, and they release toxic oxygen radicals and destructive enzymes that cause apoptosis and necrosis of the neutrophils as well as of the adjacent vessel wall cells and matrix (depicted at the right of fig. 3) [21, 22, 24, 29].

The same general pathogenic process could cause the initial lesion of the extravascular necrotizing granulomatosis of GPA and EGPA [11]. A synergistic proinflammatory condition, such as an infection or allergy, could attract primed neutrophils to the extravascular tissue. If ANCA are present in the extravascular interstitial fluid, the primed neutrophils would be activated by ANCA, which would initiate an inflammatory amplification loop causing a destructive necrotizing lesion. The acute injury would initiate a response to the injury by monocytes that transform into macrophages (including giant cells) and recruit $\mathrm{T}$ cells, which are the constituent cells of granulomatous inflammation.

\section{T Cells in ANCA Pathogenesis}

T cells are undoubtedly critically involved in the genesis of the ANCA autoimmune response, both through active B-cell help by $\mathrm{T}$ cells in order to induce a pathogenic autoantibody response with the production of $\operatorname{IgG}$ 
Fig. 3. Putative pathogenic sequence for acute vascular injury in AAV. Beginning in the upper left, resting neutrophils have ANCA autoantigens sequestered in the cytoplasmic granules. Exposure to priming factors, for example cytokines induced by infection or phlogogenic factors released by complement activation, causes priming of neutrophils with release of ANCA antigens (e.g. MPO and PR3) on the surface of neutrophils and in the microenvironment around the neutrophils. ANCA bind to ANCA antigens and activate neutrophils by $\mathrm{F} c \gamma \mathrm{R}$ engagement and $\mathrm{F}\left(\mathrm{ab}^{\prime}\right)_{2}$ binding at the neutrophil cell surface. ANCA-activated neutrophils release factors that activate the alternative complement pathway, which generates $\mathrm{C} 5 \mathrm{a}$, a chemoattractant for neutrophils. C5a also primes the arriving neutrophils for activation by ANCA. Activated neutrophils adhere to and penetrate vessel walls, and they release toxic oxygen radicals and destructive enzymes that cause apoptosis and necrosis of the neutrophils as well as of the adjacent vessel wall cells and matrix. Modified from Jennette et al. [61] with permission.

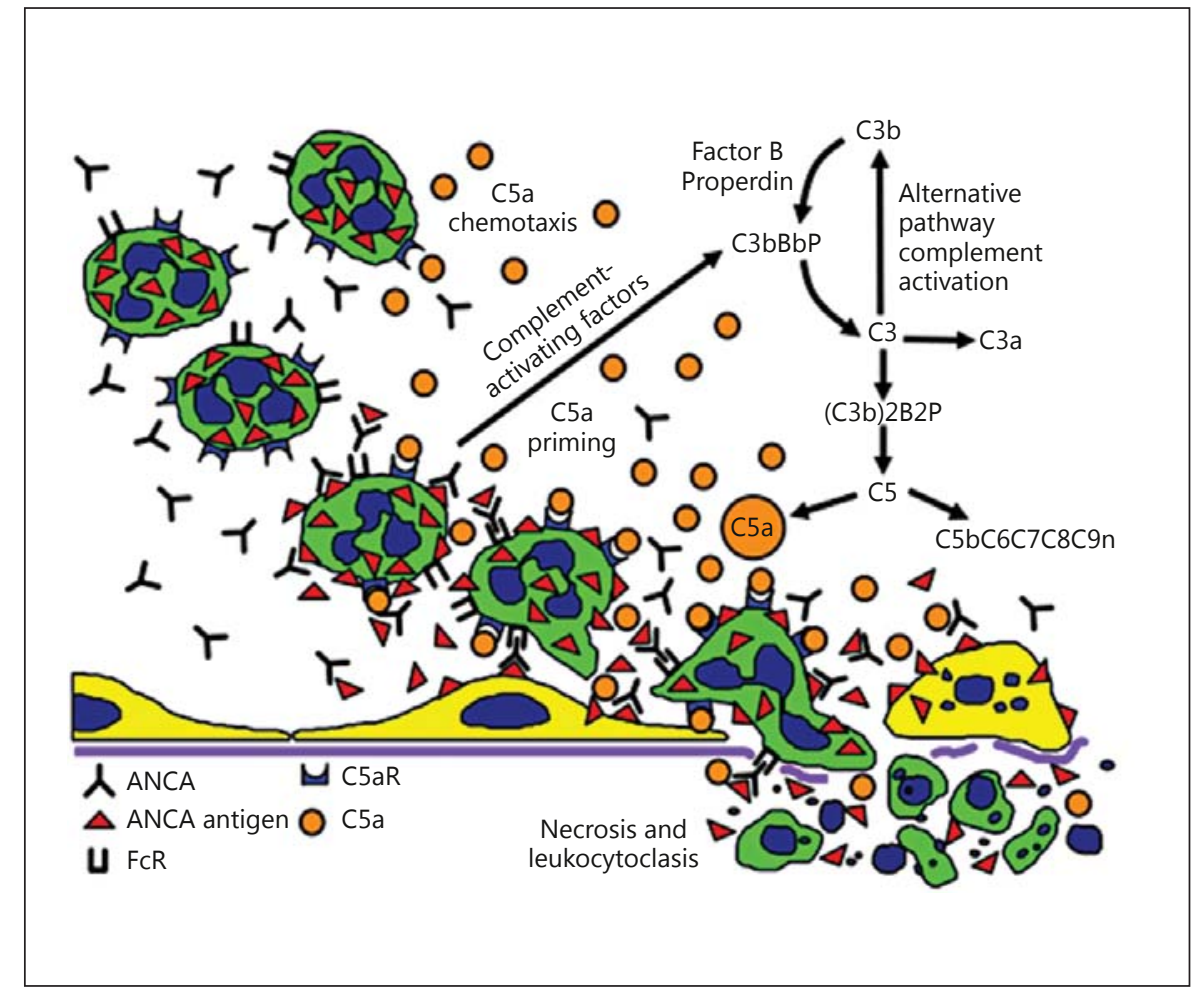

subclass antibodies and through ineffective suppression of the autoimmune ANCA response by regulatory T cells [62]. Free et al. [63] have observed that AAV patients have both disruption of the suppressive regulatory $\mathrm{T}$ cell network as well as an increased frequency of a distinct proinflammatory effector $\mathrm{T}$ cell subset.

The research group of Kitchen and Holdsworth [6467] have used a mouse model to study potential pathogenic roles for T cells in AAV. They induced glomerulonephritis by immunizing mice with human MPO, which induced B- and T-cell autoimmunity to mouse MPO. When these mice were given a dose of anti-glomerular basement membrane antibody that was not pathogenic in unimmunized control mice, neutrophils, CD4-positive cells, and macrophages accumulated in glomeruli and induced glomerulonephritis with crescents. They concluded that ANCA induce glomerular neutrophil infiltration and MPO deposition. Anti-MPO CD4-positive cells subsequently recognize the MPO as a planted antigen in glomeruli and amplified glomerular injury [64]. More recently, the same researchers investigated the role of autoreactive MPO-specific CD4-positive $\mathrm{T}$ cells in another mouse model of glomerulonephritis. They reported that transfer of epitope-specific MPO-specific CD4-positive T cells into immunodeficient Rag1 knockout mice induced

Pathogenesis of ANCA-Associated Vasculitis focal necrotizing glomerulonephritis when glomerular MPO deposition was induced either by passive transfer of MPO-ANCA and LPS or by planting the MPO epitope conjugated to a murine anti-glomerular basement membrane monoclonal antibody. They concluded that ANCAactivated neutrophils not only induce injury but also deposit MPO in glomeruli, allowing autoreactive anti-MPO CD4-positive T cells to participate in the induction of glomerular lesions [65]. The homology between the pathogenic human MPO B-cell epitope recognized by MPOANCA with the nephritogenic murine T-cell MPO epitope supports the relevance of this model to human disease.

The same research group also showed the importance of $\mathrm{T}$ cells in the pathogenesis of their model of AAV by blocking the induction of MPO autoimmunity by impairing central thymic $\mathrm{T}$ cells or peripheral regulatory $\mathrm{T}$ cells [66], or by inducing tolerance to the nephritogenic MPO peptide by nasal insufflation of the peptide [67].

\section{Genetic Association in AAV}

Patients with ANCA have a wide spectrum of NCGN severity and distribution of systemic vasculitis. For example, at the time of renal biopsy, $90 \%$ of patients have 
crescents, ranging from crescents in $100 \%$ to $<5 \%$ of glomeruli with an average of 50\% [68]. Most patients have systemic vasculitis, but a minority has renal-limited disease. Patients with systemic disease may have an MPA, GPA, or EGPA phenotype [2]. This marked disease heterogeneity may be influenced at least in part by genetic factors, which is in accord with GWAS data showing an association between AAV and genetic factors [10]. A genetic influence also has been suggested by familial occurrences [69] and a greater frequency in first-degree relatives [70]. A US cohort study showed that GPA was more prevalent in Caucasians than Blacks [71]. In New Zealand cohorts in 2003, the 5-year GPA incidence among New Zealand Maori or Asians was approximately half that among New Zealand Europeans, whereas it was twice that among New Zealand Pacific Islanders [71]. The overall prevalence was 2 times higher among subjects of European ancestry than among non-Europeans in a French urban multiethnic population in 2000 [72]. These studies support a role for genetic factors in AAV pathogenesis.

The HLA genetic region has a 'susceptibilizing' and modulatory role in many autoimmune diseases, including AAV. A strong association of the HLA-DRB1*15 allele was found in PR3-ANCA disease, with a 73.3-fold higher risk in African-American patients in a small cohort of 32 African-American and 96 Caucasian patients, suggesting $H L A-D R B 1^{*} 15$ alleles contribute to the pathogenesis of PR3-ANCA disease [73]. In a study genotyping the same area from 152 Chinese AAV patients, HLA$\mathrm{DRB} 1 * 1101$ and $\mathrm{DRB} 1 * 1202$ were significantly more frequent in patients with MPA and GPA, respectively [74]. The strong association of AAV with a single nucleotide polymorphism (SNP) in the HLA-DPB1 area was identified in two GWAS conducted by the European Vasculitis Genetic Consortium (EVGC) [10] and the Vasculitis Clinical Research Consortium (VCRC) [75]. The EVGC GWAS also showed the striking finding that the SNPs in the loci of HLA-DP, SERPINA1 (the gene encoding $\alpha_{1}$ antitrypsin, a major inhibitor of PR3), and PRTN3 (the gene encoding PR3) were strongly associated with PR3ANCA, and that a SNP in HLA-DQ was more significantly associated with MPO-ANCA. These genetic associations were stronger for ANCA specificity than for AAV clinical syndromes, suggesting that PR3-AAV and MPO-AAV are genetically distinct autoimmune diseases [10]. The strong associations of PR3-ANCA and MPOANCA disease with distinct HLA molecules suggest that HLA-determined immune responses against PR3 and MPO have a central role in the pathogenesis of ANCA disease.
A mouse model of AAV also has demonstrated a marked influence of the genetic background on the susceptibility to and severity of NCGN induced by anti-MPO [76]. Intravenous injections of anti-MPO IgG induced glomerular crescents in $>60 \%$ of glomeruli in $129 \mathrm{~S} 6 / \mathrm{SvEv}$ and CAST/EiJ mice, but in $<1 \%$ of glomeruli in $\mathrm{A} / \mathrm{J}$, $\mathrm{DBA} / 1 \mathrm{~J}, \mathrm{DBA} / 2 \mathrm{~J}, \mathrm{NOD} / \mathrm{Lt}$, and $\mathrm{PWK} / \mathrm{PhJ}$ mice. C57BL6J, 129S1/SvImJ, LP/J, WSB/EiJ, NZO/HILtJ, and $\mathrm{C} 3 \mathrm{H}$ mice showed an intermediate severity. Experiments using bone marrow chimeric mice and in vitro studies of neutrophil activation by anti-MPO IgG indicated that the severity of NCGN is mediated by genetically determined differences in the ability of neutrophils to be activated by anti-MPO. The absence of a dominant quantitative trait locus suggested that the observed differences in severity are the result of multiple gene interactions rather than a single gene effect [76].

\section{Immunogenesis of the ANCA Autoimmune Response}

As already reviewed, substantial evidence supports a pathogenic role for ANCA in AAV; however, the origin of the ANCA autoimmune response is less well understood. Several hypotheses have been proposed for the nature and origin of the autoantigens that induce the pathogenic ANCA response, including exposure to exogenous antigens such as infectious pathogens and drugs, endogenous autoantigens such as antisense peptides and peptides derived from alternatively spliced transcripts, or display of self-antigens along with adjuvant effects from apoptotic cells or neutrophil extracellular traps that are presenting the antigens. In fact, there may be multiple different mechanisms that can induce a pathogenic autoimmune response.

Several microbial agents such as Staphylococcus aureus [77] and Ross River virus [78] have been implicated in the pathogenesis of AAV. The molecular mimicry between bacterial and self-antigens has been proposed as a mechanism for the induction of pathogenic ANCA. Kain et al. [7] reported the presence of antibodies to LAMP2 in the circulation of AAV patients. The authors were able to induce glomerulonephritis in rabbits by injection of rabbit anti-human LAMP2 that cross-reacted with rat LAMP2. Human LAMP2 is located in neutrophils, endothelial cells, and other cell types, and the epitope that is recognized by ANCA has complete homology with FimH, a bacterial adhesion molecule. Rats immunized with FimH produced antibodies to rat and human LAMP2 and developed pauci-immune NCGN. These observations sug- 
gest that infection with fimbriated bacteria bearing FimH may trigger cross-reactive autoimmune responses to LAMP2 and cause AAV. These observations could not be reproduced by another research group [8]. Most recently, another observation by Kim et al. [79] revealed that when C57BL/6 mice were immunized with a recombinant serine protease of Saccharomonospora viridis, which has $>30 \%$ homology with human PR3, all mice produced high levels of autoantibodies to mouse PR3, which showed a cytoplasmic ANCA staining pattern on mouse neutrophils. More interestingly, some of those mice (40\%) developed lung granulomas.

Another mechanism proposed for the genesis of pathogenic ANCA is the initiation of the autoimmune response by peptides that are complementary to the autoantigens [80]. In this study, patients with AAV due to PR3-ANCA were found to have not only circulating antibodies against PR3 peptides (anti-PR3) but also antibodies against antisense peptides. Specific memory $\mathrm{T}$ cells against a PR3 antisense peptide have also been detected in patients with PR3-ANCA [81]. The PR3 sense peptides and antisense peptides [complementary PR3 (c-PR3)] are encoded by the sense strand and the antisense strand of the PR3 gene, respectively. The idiotypic antibodies against c-PR3 can induce anti-idiotypic anti- bodies that react with the original PR3. The researchers also found that immunization of mice with c-PR3 triggered the production of anti-PR3 antibodies [80]. The initiation of anti-c-PR3 immune responses could be triggered by endogenous c-PR3 peptides or exogenous peptides that mimic the c-PR3 peptides, which could be derived from a microbe. Interestingly, c-PR3 has homology with multiple microbial peptides including peptides from Ross River virus and S. aureus that are associated with AAV $[80,82]$, raising the possibility that infections with microbes may cause the ANCA autoimmune response and AAV via the idiotypic mechanism and complementary molecular mimicry. This theory of an immune response against a peptide that is antisense or complementary to the autoantigen is supported by the observation that pathogenic antiglomerular basement membrane antibodies can be induced by injecting rats with a peptide that is complementary to the autoantigen glomerular basement membrane peptide [83].

\section{Disclosure Statement}

The authors have no conflicts to report that are relevant to this review.

\section{References}

1 Jennette JC, Falk RJ, Andrassy K, Bacon PA, Churg J, Gross WL, Hagen EC, Hoffman GS, Hunder GG, Kallenberg CGM, McCluskey RT, Sinico RA, Rees AJ, van Es LA, Waldherr R, Wiik A: Nomenclature of systemic vasculitides. Proposal of an international consensus conference. Arthritis Rheum 1994;37:187192.

2 Jennette JC, Falk RJ: Small vessel vasculitis. N Engl J Med 1997;337:1512-1523.

3 Jennette JC, Falk RJ: The role of pathology in the diagnosis of systemic vasculitis. Clin Exp Rheumatol 2007;25(suppl 44):52-56.

4 Eisenberger U, Fakhouri F, Vanhille P, Beaufils H, Mahr A, Guillevin L, Lesavre P, Noël LH: ANCA-negative pauci-immune renal vasculitis: histology and outcome. Nephrol Dial Transplant 2005;20:1392-1399.

5 Falk RJ, Jennette JC: Anti-neutrophil cytoplasmic autoantibodies with specificity for myeloperoxidase in patients with systemic vasculitis and idiopathic necrotizing and crescentic glomerulonephritis. N Engl J Med 1988;318:1651-1657.

6 Jennette JC, Hoidal JH, Falk RJ: Specificity of anti-neutrophil cytoplasmic autoantibodies for proteinase 3. Blood 1990;75:2263-2264.

Pathogenesis of ANCA-Associated Vasculitis
Kain R, Exner M, Brandes R, Ziebermayr R, Cunningham D, Alderson CA, Davidovits A, Raab I, Jahn R, Ashour O, Spitzauer S, Sunder-Plassmann G, Fukuda M, Klemm P, Rees AJ, Kerjaschki D: Molecular mimicry in pauci-immune focal necrotizing glomerulonephritis. Nat Med 2008;14:1088-1096.

8 Roth AJ, Brown MC, Smith RN, Badhwar AK, Parente O, Chung HC, Bunch DO, McGregor JG, Hogan SL, Hu Y, Yang JJ, Berg EA, Niles J, Jennette JC, Preston GA, Falk RJ: AntiLAMP-2 antibodies are not prevalent in patients with antineutrophil cytoplasmic autoantibody glomerulonephritis. J Am Soc Nephrol 2012;23:545-555.

-9 Lionaki S, Blyth ER, Hogan SL, Hu Y, Senior JBA, Jennette CE, Nachman PH, Jennette JC, Falk RJ: Classification of antineutrophil cytoplasmic autoantibody vasculitides: the role of antineutrophil cytoplasmic autoantibody specificity for myeloperoxidase or proteinase 3 in disease recognition and prognosis. Arthritis Rheum 2012;64:3452-3462.

10 Lyons PA, Rayner TF, Trivedi S, Holle JU, Watts RA, Jayne DR, Baslund B, Brenchley P, Bruchfeld A, Chaudhry AN, et al: Genetically distinct subsets within ANCA-associated vasculitis. N Engl J Med 2012;367:214-223.
Jennette JC, Falk RJ: Pathogenesis of ANCAassociated vasculitis: observations, theories and speculations. Presse Med 2013;42(pt 2): 493-498.

12 Bansal PJ, Tobin MC: Neonatal microscopic polyangiitis secondary to transfer of maternal myeloperoxidase-antineutrophil cytoplasmic antibody resulting in neonatal pulmonary hemorrhage and renal involvement. Ann Allergy Asthma Immunol 2004;93:398-401.

13 Silva F, Specks U, Sethi S, Irazabal MV, Fervenza FC: Successful pregnancy and delivery of a healthy newborn despite transplacental transfer of antimyeloperoxidase antibodies from a mother with microscopic polyangiitis. Am J Kidney Dis 2009;54:542-545.

14 Roth AJ, Ooi J, Hess JJ, van Timmeren MM, Berg EA, Jennette CE, McGregor JA, Burkart M, Hogan SL, Hu Y, Winnik W, Nachman PH, Stegeman CA, Niles J, Heeringa P, Kitching AR, Holdsworth S, Jennette JC, Preston GA, Falk RJ: ANCA epitope specificity determines pathogenicity, detectability and clinical predictive value. J Clin Invest 2013;123:1773-1783.

15 ten Holder SM, Joy MS, Falk RJ: Cutaneous and systemic manifestations of drug-induced vasculitis. Ann Pharmacother 2002;36:130147 
16 Pendergraft WF 3rd, Niles JL: Trojan horses: drug culprits associated with antineutrophil cytoplasmic autoantibody (ANCA) vasculitis. Curr Opin Rheumatol 2014;26:42-49.

17 Visavachaipan N, Ong-Ajyooth L, Chanchairujuira T, Parichatikanond P, Choensuchon B: Clinical features and outcomes in patient with antineutrophil cytoplasmic autoantibody-positive glomerulonephritis associated with propylthiouracil treatment in Siriraj Hospital. J Med Assoc Thai 2010;93(suppl 1):S139-S146.

18 Jayne DR, Gaskin G, Rasmussen N, Abramowicz D, Ferrario F, Guillevin L, Mirapeix E, Savage CO, Sinico RA, Stegeman CA, Westman KW, van der Woude FJ, de Lind van Wijngaarden RA, Pusey CD; European Vasculitis Study Group: Randomized trial of plasma exchange or high-dosage methylprednisolone as adjunctive therapy for severe renal vasculitis. J Am Soc Nephrol 2007;18:21802188.

19 Jones RB: Rituximab in the treatment of antineutrophil cytoplasm antibody-associated vasculitis. Nephron Clin Pract 2014;128:243249.

20 Falk RJ, Terrell RS, Charles LA, Jennette JC: Anti-neutrophil cytoplasmic autoantibodies induce neutrophils to degranulate and produce oxygen radicals in vitro. Proc Natl Acad Sci USA 1990;87:4115-4119.

-21 Ewert BH, Jennette JC, Falk RJ: Anti-myeloperoxidase antibodies stimulate neutrophils to damage human endothelial cells. Kidney Int 1992;41:375-383.

22 Savage CO, Gaskin G, Pusey CD, Pearson JD: Myeloperoxidase binds to vascular endothelial cells, is recognized by ANCA and can enhance complement dependent cytotoxicity. Adv Exp Med Biol 1993;336:121-123.

$\checkmark 23$ Porges AJ, Redecha PB, Kimberly WT, Csernok E, Gross WL, Kimberly RP: Anti-neutrophil cytoplasmic antibodies engage and activate human neutrophils via Fc $\gamma$ RIIa. J Immunol 1994:153:1271-1280.

24 Ewert BH, Becker ME, Jennette JC, Falk RJ: Antimyeloperoxidase antibodies induce neutrophil adherence to cultured human endothelial cells. Ren Fail 1995;17:125-133.

-25 Kocher M, Siegel ME, Edberg JC, Kimberly RP: Cross-linking of Fc $\gamma$ receptor IIa and Fc $\gamma$ receptor IIIb induces different proadhesive phenotypes on human neutrophils. J Immunol 1997;159:3940-3948.

-26 Kettritz R, Jennette JC, Falk RJ: Cross-linking of ANCA-antigens stimulates superoxide release by human neutrophils. J Am So Nephrol 1997;8:386-394.

-27 Kettritz R, Schreiber A, Luft FC, Haller H: Role of mitogen-activated protein kinases in activation of human neutrophils by antineutrophil cytoplasmic antibodies. J Am Soc Nephrol 2001;12:37-46.
28 Williams JM, Ben-Smith A, Hewins P, Dove SK, Hughes P, McEwan R, Wakelam MJO, Savage COS: Activation of the G heterotrimeric $\mathrm{G}$ protein by ANCA IgG $\mathrm{F}\left(\mathrm{ab}^{\prime}\right)_{2}$ fragments is necessary but not sufficient to stimulate the recruitment of those downstream mediators used by intact ANCA IgG. J Am Soc Nephrol 2003;14:661-669.

29 Lu X, Garfield A, Rainger GE, Savage CO, Nash GB: Mediation of endothelial cell damage by serine proteases, but not superoxide released from antineutrophil cytoplasmic antibody-stimulated neutrophils. Arthritis Rheum 2006;54:1619-1628.

30 Schreiber A, Xiao H, Jennette JC, Schneider W, Luft FC, Kettritz R: C5a receptor mediates neutrophil activation and ANCA-induced glomerulonephritis. J Am Soc Nephrol 2009; 20:289-298.

-31 van der Veen BS, Chen M, Müller R, van Timmeren MM, Petersen AH, Lee PA, Satchell SC, Mathieson PW, Saleem MA, Stegeman CA, Zwerina J, Molema G, Heeringa P: Effects of p38 mitogen-activated protein kinase inhibition on anti-neutrophil cytoplasmic autoantibody pathogenicity in vitro and in vivo. Ann Rheum Dis 2011;70:356-365.

32 Hao J, Meng LQ, Xu PC, Chen M, Zhao MH: p38MAPK, ERK and PI3K signaling pathways are involved in C5a-primed neutrophils for ANCA-mediated activation. PLoS One 2012;7:e38317.

33 Al-Ani B: Simvastatin inhibits neutrophil degranulation induced by antineutrophil cytoplasm auto-antibodies and N-formyl-methionine-leucine phenylalanine (fMLP) peptide. Saudi Med J 2013;34:477-483.

34 Casselman BL, Kilgore KS, Miller BF, Warren JS: Antibodies to neutrophil cytoplasmic antigens induce monocyte chemoattractant protein-1 secretion from human monocytes. J Lab Clin Med 1995;126:495-502.

35 Ralston DR, Marsh CB, Lowe MP, Wewers MD: Antineutrophil cytoplasmic antibodies induce monocyte IL-8 release. Role of surface proteinase- $3, \alpha_{1}$-antitrypsin, and $\mathrm{Fc} \gamma$ receptors. J Clin Invest 1997;100:1416-1424.

-36 Jennette JC, Falk RJ: ANCAs are also antimonocyte cytoplasmic autoantibodies. Clin J Am Soc Nephrol 2015;10:4-6.

37 Weidner S, Carl M, Riess R, Rupprecht HD: Histologic analysis of renal leukocyte infiltration in antineutrophil cytoplasmic antibodyassociated vasculitis: importance of monocyte and neutrophil infiltration in tissue damage. Arthritis Rheum 2004;50:3651-3657.

38 Zhao L, David MZ, Hyjek E, Chang A, Meehan SM: M2 macrophage infiltrates in the early stages of ANCA-associated pauci-immune necrotizing GN. Clin J Am Soc Nephrol 2015; 10:54-62.

39 Muller Kobold AC, Kallenberg CG, Tervaert JW: Monocyte activation in patients with Wegener's granulomatosis. Ann Rheum Dis 1999;58:237-245.
40 Jennette JC, Xiao H, Falk R, Gasim AM: Experimental models of vasculitis and glomerulonephritis induced by antineutrophil cytoplasmic autoantibodies. Contrib Nephrol 2011;169:211-220.

-41 Xiao H, Heeringa P, Hu P, Liu Z, Zhao M, Aratani Y, Maeda N, Falk RJ, Jennette JC: Antineutrophil cytoplasmic autoantibodies specific for myeloperoxidase cause glomerulonephritis and vasculitis in mice. J Clin Invest 2002;110:955-963.

42 Schreiber A, Xiao H, Falk RJ, Jennette JC: Bone marrow-derived cells are sufficient and necessary targets to mediate glomerulonephritis and vasculitis induced by anti-myeloperoxidase antibodies. J Am Soc Nephrol 2006; 17:3355-3364.

43 Little MA, Smyth CL, Yadav R, Ambrose L, Cook HT, Nourshargh S, Pusey CD: Antineutrophil cytoplasm antibodies directed against myeloperoxidase augment leukocyte-microvascular interactions in vivo. Blood 2005;106: 2050-2058.

44 Little MA, Smyth L, Salama AD, Mukherjee S, Smith J, Haskard D, Nourshargh S, Cook HT, Pusey CD: Experimental autoimmune vasculitis: an animal model of anti-neutrophil cytoplasmic autoantibody-associated systemic vasculitis. Am J Pathol 2009;174:1212-1220.

45 Pfister H, Ollert M, Fröhlich LF, QuintanillaMartinez L, Colby TV, Specks U, Jenne DE: Antineutrophil cytoplasmic autoantibodies against the murine homolog of proteinase 3 (Wegener autoantigen) are pathogenic in vivo. Blood 2004;104:1411-1418.

46 van der Geld YM, Hellmark T, Seiga D, Heeringa P, Huitema MG, Limburg P, Kallenberg CGM: Rats and mice immunized with chimeric human/mouse proteinase 3 produce autoantibodies to mouse $\operatorname{Pr} 3$ and rat granulocytes. Ann Rheum Dis 2007;66:1679-1682.

47 Primo VC, Marusic S, Franklin CC, Goldmann WH, Achaval CG, Smith RN, Arnaout MA, Nikolic B: Anti-PR3 immune responses induce segmental and necrotizing glomerulonephritis. Clin Exp Immunol 2010;159:327337.

-48 Little MA, Al-Ani B, Ren S, Al-Nuaimi H, Leite M Jr, Alpers CE, Savage CO, Duffield JS: Anti-proteinase 3 anti-neutrophil cytoplasm autoantibodies recapitulate systemic vasculitis in mice with a humanized immune system. PLoS One 2012;7:e28626.

49 Brouwer E, Huitema MG, Mulder AH, Heeringa $\mathrm{P}$, van Goor $\mathrm{H}$, Tervaert JW, Weening JJ, Kallenberg CG: Neutrophil activation in vitro and in vivo in Wegener's granulomatosis. Kidney Int 1994;45:1120-1131.

50 Xiao H, Heeringa P, Liu Z, Huugen D, Hu PQ, Maeda N, Falk RJ, Jennette JC: The role of neutrophils in the induction of glomerulonephritis by anti-myeloperoxidase antibodies. Am J Pathol 2005;167:39-45. 
-51 Tidman M, Olander R, Svalander C, Danielsson D: Patients hospitalised because of small vessel vasculitis with renal involvement in the period 1975-1995: organ involvement, antineutrophil cytoplasmic antibodies patterns, seasonal attack rates and fluctuation of annual frequencies. J Intern Med 1998;244:133141.

52 Huugen D, Xiao H, van Esch A, Falk RJ, Peutz-Kootstra CJ, Buurman WA, Tervaert JW, Jennette JC, Heeringa P: Aggravation of anti-myeloperoxidase antibody-induced glomerulonephritis by bacterial lipopolysaccharide: role of tumor necrosis factor- $\alpha$. Am J Pathol 2005;167:47-58.

53 Xiao H, Schreiber A, Heeringa P, Falk RJ, Jennette JC: Alternative complement pathway in the pathogenesis of disease mediated by antineutrophil cytoplasmic autoantibodies. Am J Pathol 2007;170:52-64.

54 Chen M, Xing GQ, Yu F, Liu G, Zhao MH: Complement deposition in renal histopathology of patients with ANCA-associated pauciimmune glomerulonephritis. Nephrol Dial Transplant 2009;24:1247-1252.

55 Xing GQ, Chen M, Liu G, Heeringa P, Zhang $\mathrm{JJ}$, Zheng X, et al: Complement activation is involved in renal damage in human antineutrophil cytoplasmic autoantibody associated pauci-immune vasculitis. J Clin Immunol 2009;29:282-291.

-56 Gou SJ, Yuan J, Chen M, Yu F, Zhao MH: Circulating complement activation in patients with anti-neutrophil cytoplasmic antibodyassociated vasculitis. Kidney Int 2013;83:129137.

57 Gou SJ, Yuan J, Wang C, Zhao MH, Chen M: Alternative complement pathway activation products in urine and kidneys of patients with ANCA-associated GN. Clin J Am Soc Nephrol 2013;8:1884-1891.

58 Molad Y, Tovar A, Ofer-Shiber S: Association of low serum complement $\mathrm{C} 3$ with reduced patient and renal survival in antimyeloperoxidase-associated small-vessel vasculitis. Nephron Clin Pract 2014;126:67-74.

59 Chen SF, Wang FM, Li ZY, Yu F, Zhao MH, Chen M: Plasma complement factor $\mathrm{H}$ is associated with disease activity of patients with ANCA-associated vasculitis. Arthritis Res Ther 2015; 17:129.

-60 Xiao H, Dairaghi DJ, Powers JP, Ertl LS, Baumgart T, Wang Y, Seitz LC, Penfold ME, Gan L, Hu P, Lu B, Gerard NP, Gerard C, Schall TJ, Jaen JC, Falk RJ, Jennette JC: C5a receptor (CD88) blockade protects against MPO-ANCA GN. J Am Soc Nephrol 2014;25: 225-231.

Pathogenesis of ANCA-Associated Vasculitis
61 Jennette JC, Xiao H, Hu P: Complement in ANCA-associated vasculitis. Semin Nephrol 2013;33:557-564

62 Lepse N, Abdulahad WH, Kallenberg CG, Heeringa P: Immune regulatory mechanisms in ANCA-associated vasculitides. Autoimmun Rev 2011;11:77-83.

63 Free ME, Bunch DO, McGregor JA, Jones BE, Berg EA, Hogan SL, Hu Y, Preston GA, Jennette JC, Falk RJ, Su MA: Patients with antineutrophil cytoplasmic antibody-associated vasculitis have defective Treg cell function exacerbated by the presence of a suppressionresistant effector cell population. Arthritis Rheum 2013;65:1922-1933.

64 Ruth AJ, Kitching AR, Kwan RY, Odobasic D, Ooi JD, Timoshanko JR, Hickey MJ, Holdsworth SR: Anti-neutrophil cytoplasmic antibodies and effector CD4+ cells play nonredundant roles in anti-myeloperoxidase crescentic glomerulonephritis. J Am Soc Nephrol 2006; 17:1940-1949.

65 Ooi JD, Chang J, Hickey MJ, Borza DB, Fugger L, Holdsworth SR, Kitching AR: The immunodominant myeloperoxidase T-cell epitope induces local cell-mediated injury in antimyeloperoxidase glomerulonephritis. Proc Natl Acad Sci USA 2012;109:E2615-E2624.

66 Tan DS, Gan PY, O'Sullivan KM, Hammett MV, Summers SA, Ooi JD, Lundgren BA, Boyd RL, Scott HS, Kitching AR, Chidgey AP, Holdsworth SR: Thymic deletion and regulatory $\mathrm{T}$ cells prevent antimyeloperoxidase $\mathrm{GN}$. J Am Soc Nephrol 2013;24:573-585.

67 Gan PY, Tan DS, Ooi JD, Alikhan MA, Kitching AR, Holdsworth SR: Myeloperoxidase peptide-based nasal tolerance in experimental ANCA-associated GN. J Am Soc Nephrol 2015, Epub ahead of print.

68 Jennette JC: Rapidly progressive and crescentic glomerulonephritis. Kidney Int 2003;63: 1164-1177.

69 Knight A, Sandin S, Askling J: Risks and relative risks of Wegener's granulomatosis among close relatives of patients with the disease. Arthritis Rheum 2008;58:302-307.

70 Cotch MF, Rao JK: New insights into the epidemiology of systemic vasculitis. Curr Opin Rheumatol 1996;8:19-25.

71 O’Donnell JL, Stevanovic VR, Frampton C, Stamp LK, Chapman PT: Wegener's granulomatosis in New Zealand: evidence for a latitude dependent incidence gradient. Intern Med J 2007;37:242-246.

72 Mahr A, Guillevin L, Poissonnet M, Aymé S: Prevalences of polyarteritis nodosa, microscopic polyangiitis, Wegener's granulomatosis, and Churg-Strauss syndrome in a French urban multiethnic population in 2000: a capture-recapture estimate. Arthritis Rheum 2004;51:92-99.
73 Cao Y, Schmitz JL, Yang JJ, Hogan SL, Bunch DO, Hu Y, Jennette CE, Berg EA, Arnett FC Jr, Jennette JC, Falk RJ, Preston GA: DRBI*15 allele is a risk factor for PR3-ANCA disease in African Americans. J Am Soc Nephrol 2011; 22:1161-1167.

74 Luo H, Chen M, Yang R, Xu PC, Zhao MH: The association of HLA-DRB1 alleles with antineutrophil cytoplasmic antibody-associated systemic vasculitis in Chinese patients. Hum Immunol 2011;72:422-425.

-75 Xie G, Roshandel D, Sherva R, Monarch PA, Lu EY, Kung T, Carrington K, Zhang SS, Pulit SL, Ripke S, et al: Association of granulomatosis with polyangiitis (Wegener's) with HLA$D P B 1^{*} 04$ and SEMA6A gene variants: evidence from genome-wide analysis. Arthritis Rheum 2013;65:2457-2468.

-76 Xiao H, Ciavatta D, Aylor DL, Hu P, de Villena FP, Falk RJ, Jennette JC: Genetically determined severity of anti-myeloperoxidase glomerulonephritis. Am J Pathol 2013;182: 1219-1226.

-77 Popa ER, Stegeman CA, Kallenberg CG, Tervaert JW: Staphylococcus aureus and Wegener's granulomatosis. Arthritis Res 2002;4: 77-79.

78 Davies DJ, Moran JE, Niall JF, Ryan GB: Segmental necrotizing glomerulonephritis with antineutrophil antibody: possible arbovirus aetiology? Br Med J (Clin Res Ed) 1982;285: 606.

79 Kim YC, Choi YS, Alam J, Kim Y, Baek KJ Koh J, Song YW, Chung DH, Choi Y: Induction of proteinase 3-anti-neutrophil cytoplasmic autoantibodies by proteinase 3-homologous bacterial protease in mice. Immunol Res 2015, Epub ahead of print

80 Pendergraft WF 3rd, Preston GA, Shah RR, Tropsha A, Carter CW Jr, Jennette JC, Falk RJ: Autoimmunity is triggered by cPR-3(105201 ), a protein complementary to the autoantigen proteinase 3 . Nat Med 2004;10:72-79.

81 Yang JJ, Bautz DJ, Lionaki S, Hogan SL, Chin H, Tisch RM, Schmitz JL, Pressler BM, Jennette JC, Falk RJ, Preston GA: ANCA patients have $\mathrm{T}$ cells responsive to complementary PR 3 antigen. Kidney Int 2008;74:1159-1169.

82 Preston GA, Pendergraft WF 3rd, Falk RJ: New insights that link microbes with the generation of antineutrophil cytoplasmic autoantibodies: the theory of autoantigen complementarity. Curr Opin Nephrol Hypertens 2005;14:217-222.

83 Reynolds J, Preston GA, Pressler BM, Hewins P, Brown M, Roth A, Alderman E, Bunch D, Jennette JC, Cook HT, Falk RJ, Pusey CD: Autoimmunity to the alpha 3 chain of type IV collagen in glomerulonephritis is triggered by 'autoantigen complementarity'. J Autoimmun 2015;59:8-18. 